\title{
Risk to Develop Type 2 Diabetes Mellitus according to FINDRISC tool in Guatemalan Physicians aged 40-60 years
}

Estuardo Daniel Castro, ${ }^{1}$ Gamaliél Alejandro Velásquez, ${ }^{1}$ Edgar Lineker Santos, ${ }^{1}$ Gustavo Adolfo Oliva, ${ }^{1}$ Clara Elizabeth Chang, Harry Francisco Soto.

\begin{abstract}
Background: In Latin America 22.4 million people has abnormal tolerance to insulin, these ones could turn into diabetics if they do not change their lifestyles. Added to this, there are 15 million who present Diabetes Mellitus and this amount will increase to 20 million in 10 years. This epidemic behavior is caused by many factors in which stand out lifestyles, the population aging, and lack of prevention programs. Since 1994, physicians in Guatemala have demonstrated to have inadequate lifestyles in different researches, standing out sedentarism, overweight and obesity, and hypercaloric diets. 0bjective: To evaluate the risk of developing type 2 Diabetes Mellitus using the Finnish Diabetes Risk Score (FINDRISC) in Guatemalan doctors of three medical institutions in the months of June and July 2016. Methods: Cross-sectional study, where 176 doctors were interviewed using the FINDRISC. Participant's body mass index and abdominal circumference were measured. Results: Mean age was 50 years, 63\% (110) male; 55\% (96) were sedentary, more than three quarters consumed fruits and vegetables daily, $22 \%$ (38) were hypertensive, $10 \%(17)$ had a history of impaired glucose and $61 \%$ family history of diabetes (108); $47 \%$ (82) were overweight and $31 \%$ (54) had some degree of obesity. Central obesity was present in 63\% (111). There was a statistically significant relationship between age and risk of type 2 diabetes (OR: 3.4 p: 0.001) as well as a relationship between physical activity and abdominal circumference (OR: 2.84, p: 0.001 ). Out of the total population, $80 \%$ (141) of doctors were in some degree of risk, from these, $53 \%$ with slightly elevated, $29 \%$ moderate, $16 \%$ with high and $2 \%$ very high risk. Conclusions: Eight out of ten doctors studied were at risk of developing type 2 diabetes over a period of ten years. There is a relationship between: age and risk of disease, as well as between physical activity and abdominal circumference.
\end{abstract}

Keywords: Diabetes mellitus; Physicians; Risk factors (Source MeSH-NLM).

About the Author: Estuardo Castro Ruiz is a recently graduated medical doctor from Universidad de San Carlos of Guatemala, Guatemala. He is currently studying a research course at Universidad de San Carlos and working in a third level hospital, specialist in Tuberculosis, where he is conducting research on sensitive tuberculosis and multidrug resistant tuberculosis.

\section{Introduction}

Diabetes mellitus (DM) is a chronic noncommunicable disease, characterized by hyperglycemia, relative deficit (insulin resistance) or absolute deficit of insulin. This chronic pathology requires continued medical care with multifactorial risk reduction strategies beyond glycemic control.'

It was estimated globally that in the year 20121.5 million people died as a direct consequence of the DM. By 2030, it is projected that this disease will be the seventh cause of mortality and that there will be a worldwide population of 366 million people who will suffer DM. There are about 15 million DM individuals in Latin America; this data will increase to 20 million in 10 years. This epidemic behavior is probably due to several factors including race, change in lifestyles, and population aging. (World Health Organization, WHO. Available from: http:// www.who.int/mediacentre/factsheets/fs312/es, updated 2015 Jan; cited 2016 Jul 10).

The Mexican National Health Survey of 2000 shows a prevalence of DM in adults over 19 years of age of $7.5 \%$. It was found that age is directly related to the risk of DM, $2.3 \%$ before age 40 and $21.2 \%$ after 60 years.2,3 In Guatemala, the CAMDI (The Central American Diabetes Initiative) study found that $24.5 \%$ of the participants had a known family history of the disease, the mean Body Mass Index (BMI) was $26.5 \mathrm{~kg} / \mathrm{m2}$, the prevalence of DM was $8.4 \%$, and impaired fasting glucose / intolerance glucose was $23.6 \%$. It was demonstrated that, in the population diagnosed with DM, the percentage of obesity and overweight was $78 \%$ ( 47 and $31 \%$, respectively). Also, $55 \%$ of the people were sedentary and $27 \%$ had insufficient physical activity. These risk factors are the cornerstone to explain the increase of DM in the population.

A research which analyzed these risk factors in physicians in 3 Guatemalan hospitals, evidenced that $53 \%$ of physicians were overweight, and $33 \%$ Moderate obesity or grade 2 , these data were associated with each other, finding that $53 \%$ of physicians who were overweight, $14 \%$ had average physical activity and $57 \%$ had poor physical condition. ${ }^{5}$

According to statistics of Colegio de Médicos Guatemala, during a period of 7 years, the mortality of the medical profession was due in $47 \%$ to chronic degenerative diseases among which DM occupied the fourth place; Acute myocardial infarction and cerebrovascular event occupied the Second and third place respectively, these 2 last are common complications of diabetic patients. of this percentage, $42 \%$ of physicians were between the 40 to 60 years of age. ${ }^{6}$ 
Table 1. Values of statistical association measures found for related variables in physicians.

\begin{tabular}{lcc}
\hline Associations* & Odds ratio & Cl 95\% \\
\hline Age - Risk & 3.4 & $1.55-7.44$ \\
\hline Gender - Risk & 0.84 & 0.001 \\
\hline Physical activity - BMI & 1.64 & $0.67-1.66$ \\
\hline Physical activity - Abdominal circumference & 2.84 & $0.81-3.34$ \\
\hline Diet - BMI & 2.78 & $1.51-5.34$ \\
Diet - Abdominal circumference & 1.06 & $0.79-9.73$ \\
\hline
\end{tabular}

* Associations: Age <45 years, .45 years; Risk .7 points, No risk 47 points; Physical activity if performed 30 min, does not perform 30 min; Body mass index increased . $25 \mathrm{~kg} / \mathrm{m} 2$, Body mass index normal $<25 \mathrm{~kg} / \mathrm{m} 2$; Abdominal circumference normal (men $<94 \mathrm{~cm}$ and women $<80 \mathrm{~cm}$ ), High (men $.94 \mathrm{~cm}$, women $.80 \mathrm{~cm}$ ); Diet: consumption of fruits and vegetables every day, not every day.

There is not any research which has studied the risk to develop Type 2 DM in physicians, even if this specific group has a higher prevalence of the risk factors than other groups. The physicians compromise themselves to take care of the health of the people, but who takes care of them.

This study aims to identify the risk factors for DM and the probability to develop the disease in a period of ten years in Guatemalan physicians aged 40 to 60 years. This study is relevant to increase awareness about self-care of doctors and could potentially increase a better care of patients at risk.

\section{Methodology}

A cross-sectional study, carried out in June and July of 2016 in the hospitals: General San Juan de Dios (HCSJDD), General de Enfermedades del Instituto Guatemalteco de Seguridad Social (ICSS zone 9) and Centro Universitario Metropolitano de la Universidad de San Carlos de Guatemala (CUM), where the physicians between 40 and 60 years of age, working in the institutions, were taken as the universe. The three institutions are located in Cuatemala City. Two of them are tertiary care level and the third one is an academic institution for medical education. Representing doctors in the Public, Semiprivate and Teaching sectors.

The population estimated was 337 doctors including all the specialties and departments of the three institutions. The sample was calculated by the formula7 $\mathrm{n}=[\mathrm{Nz2} \mathrm{pq}] /[\mathrm{d} 2(\mathrm{~N}-1)+\mathrm{z} 2$ pq], where $\mathrm{n}=$ sample to be calculated, $\mathrm{N}=337$ physicians (population), $\mathrm{z}=1.96(\mathrm{Cl}$ of $95 \%), \mathrm{d}=0.05$ (absolute precision), $p=0.5$ prevalence of the disease (maximum value, since there are no previous studies), $q=0.5$. A statistically representative sample of 180 physicians was obtained, and an adjusted sample was calculated taking a possible $10 \%$ rejection with the following formula: $n a=n$ * $(1 / 1-R)$, where $n a=$ adjusted sample to be calculated, $\mathrm{n}=180$ (the sample), $\mathrm{R}=10 \%$ rejection. An adjusted sample of 200 physicians was calculated, which were distributed proportionally to the population of each institution.

The study excluded physicians who had a definitive diagnosis of prediabetes, type 1 or type 2 DM. The subjects under study were selected by probabilistic, simple random sampling. The Finnish Diabetes Risk Score (FINDRISC) is a tool designed to identify risk factors to develop DM. Data collection was performed using this test. It has been validated in Finland, Spain, Italy and Germany and used in Latin American populations
(Venezuela, Cuba and Colombia) to measure the likelihood of developing type 2 DM within 10 years with a sensitivity of $81 \%$ and a specificity of $77 \%$ 8-14

The data collected includes: age, sex, BMI (measured during data collection) and abdominal circumference (measured during data collection), sedentary lifestyle (less than 30 minutes of physical activity daily), diet (daily consumption of fruits and / or vegetables), antihypertensive medication, previous alterations in blood glucose levels, and family history of diabetes. The test assigned a score to each question. The total gives a predictive result for the development of type 2 diabetes in a period of 10 years.

With the statistical software Epi Info ${ }^{\circ}$ 7.2, the data was analyzed using descriptive statistics. Associations were assessed using $2 \times 2$ tables, and they were measured using Chi Square $\left(X_{2}\right)$ and the strength of the association with Odd Ratio (OR).

\section{Ethical Considerations}

The present study did not perform any intervention in the study subjects. In all cases, the confidentiality of the information collected was maintained.

Figure 1. Distribution of epidemiological risk factors for the development type 2 diabetes mellitus.

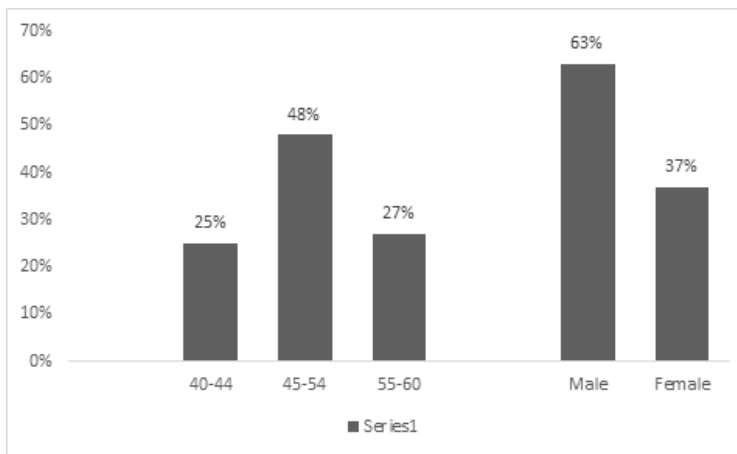

\section{Results}

There were interviewed a total of 176 physicians. Among them, $24(12 \%)$ denies their participation in the study. The mean age was 50 years $( \pm 6), 63 \%$ (110) were male; $37 \%$ (66) female (Figure 1), 55\% (96) were sedentary, more than three quarters consumed fruits and vegetables daily (Figure 2), 22\% (38) had medication for arterial hypertension, $10 \%$ (17) had a history 
of impaired glucose, and $61 \%$ (108) family history of diabetes, being $42 \%$ in first degree of consanguinity and $19 \%$ in a second degree (Figure 3); $47 \%$ (82) were overweight and 31\% (54) had some degree of obesity. Central obesity was present in $63 \%$ (111), with a mean in males of $96.32 \mathrm{~cm}( \pm 10.5)$ and in females of $86.14 \mathrm{~cm}( \pm 10)$ (Figure 4 ).

There was a statistically significant relationship between age and risk of type 2 diabetes (OR: $3.4,95 \%$ Confidence interval [95\% Cl] $1.55-7.44)$ as well as a relationship between physical activity and abdominal circumference (OR: 2.84, 95\% Cl 1.515.34) (Table 1).

Out of the study population, $80 \%$ (141) of doctors were in some degree of risk for DM, $43 \%$ at a slightly elevated risk ( 1 in 25 doctors will develop the disease), $23 \%$ moderate risk ( 1 in 6 will suffer from DM), $13 \%$ high risk (1 in 3 ) and $1 \%$ high risk (1 in 2 will develop the disease) (Figure 5 ).

Figure 2. Distribution of the lifestyles in physicians.

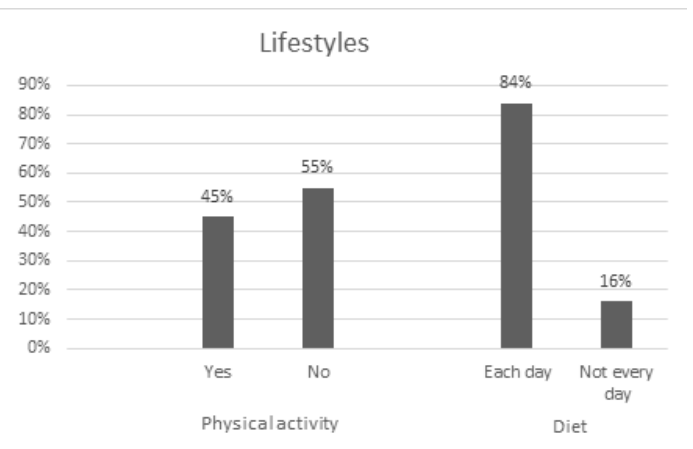

\section{Discussion}

Diabetes mellitus is a preventable chronic disease where the identification of risk factors is a priority. The present study is the first to be carried out on these risk factors in physicians and it found physicians were sedentary, obese, with an important prevalence of high abdominal circumference, and with a huge percentage of familiar history of diabetes making them susceptible to develop DM2 in 8 out 10 cases.

Within the age range, an average of 50 years was obtained. Only $25 \%$ of them were below 45 years old. It is worth mentioning that in the FINDRISC test it gives risk points when the person is over 45 years old, therefore, with the average age of 50 years of the population, is already a population at risk because of age.

More than half of the interviewees did not comply with $30 \mathrm{mi}-$ nutes of daily physical activity; A result similar to the study of the Mexican Social Security Institute, where it was found that $60 \%$ of health staff did not perform physical activity. 15 In the Villa Nueva study in Guatemala, it was found that $48 \%$ (Population without glucose alteration) and 53\% (population with impaired glucose) were sedentary; The study Cardiotesis, found a $27.68 \%$ of sedentarism in the Guatemalan population. 16 This shows that the prevalence of physical inactivity found in physicians is greater than that of the general population of Guatemala and is similar to that found in health staff in other countries of the region.
Regarding fruits and vegetables, more than 3 quarters of the population studied consume them. The daily intake of fruits and vegetables is translated into a diet high in fiber and complex carbohydrates, reducing the risk of suffering DM, the BMI, and waist circumference.17 This was not associated with risk of DM in this study, therefore, in agreement with the literature.

In general, the study population showed a familiar history of diabetes in more than half of the cases. This is an important aspect, since it increases the risk of diabetes and added to other factors (sedentary, overweight, obesity or central obesity), increases the probability of suffering the disease.

Concerning to history of diseases, hypertension has been closely associated with the risk of diabetes mellitus. It was described that $30 \%$ to $50 \%$ of hypertensive patients were diabetic. 18 This means of the $22 \%$ of hypertensive physicians found in this research, 11 to 19 subjects will have DM2. The risk increases more and more when there are other associated factors such as central obesity and sedentary lifestyle as mentioned above. However, adequate control of hypertension has been shown to delay the onset of diabetes and its silent micro- and macrovascular complications 18,19 . For this reason the FINDRISC asks the question "Do you take medication for blood pressure? Emphasizing the control that is carried on the hypertension of the subject. Only with these data could said that approximately $10 \%$ of doctors will develop DM2. $9.7 \%$ reported a history of altered glycaemia, a higher than expected figure of $7.4 \%$ in Latin Americazo, noting that physicians are more susceptible to insulin resistance than other people, this may be due to large part to genetic predisposition and part to modifiable factors (inadequate lifestyles).

Obesity and overweight statistics reveal almost half of the subjects were overweight and $31 \%$ were obese. In comparison, the Peru study conducted in physicians, found a prevalence of overweight $53 \%$, but lower than obesity with $21 \%$. A study done in Mexico on the health staff, found that a percentage of overweight and obesity of $75 \%$. In Guatemala, evidence published in 1994 showed that $53 \%$ of physicians were overweight and $33 \%$ obese. $5,16,21$ This indicates that the data has not changed in other countries and after 22 years in Guatemala, the statistics are still high. From our knowledge, this could be explained in part due to doctors' lack of interest in their health and in changing their lifestyles.

Central obesity, represented by abdominal circumference, an average of $86.13 \mathrm{~cm}$ was found for females and $96.33 \mathrm{~cm}$ for

Figure 3. Distribution of backgrounds in physicians.

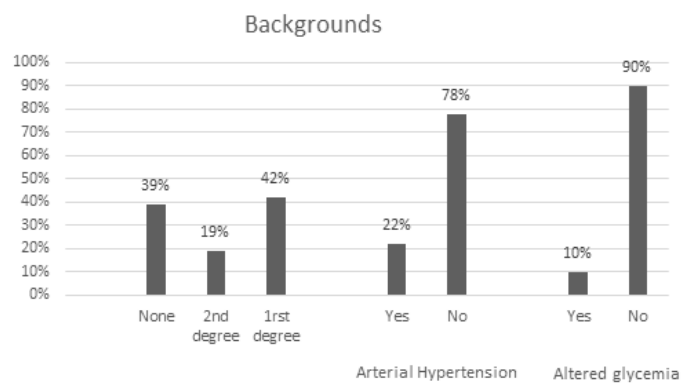


Figure 4. Distribution of the anthropometric factors in physicians.

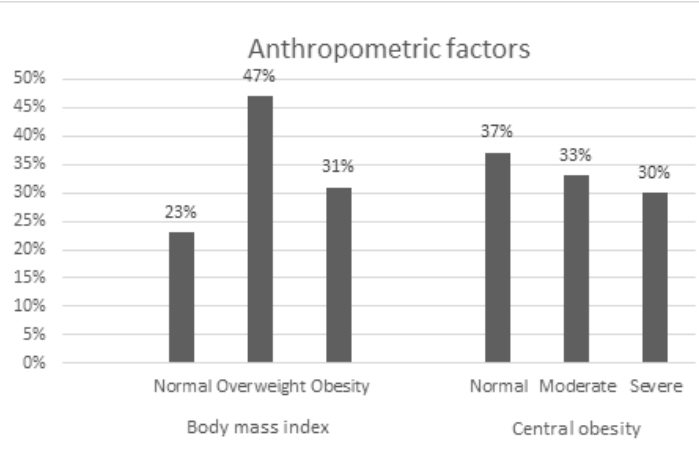

males. Very similar data can be found when comparing females with populations in Costa Rica and Chile. On the other hand, in the male sex, Costa Rica had an average of $88.1 \mathrm{~cm}$ and Chile one of $90.7 \mathrm{~cm} 22-23$; this indicates that central obesity is present in female doctors in an equal magnitude to that in other countries, but not the same in the male sex, which shows a higher prevalence.

The prevalence of increased abdominal circumference was 63.1\%. The "CADMI" study in Villa Nueva had a 59.9\% prevalence and in its hypertensive population. In the study "Cardiotesis" in Guatemala, the prevalence was $53.44 \%$ and specifically the urban population of that same study presented $61.13 \%{ }^{16}$. This difference between the general population and the urban population is due to different factors, which must be studied and if these are the same in doctors as in the urban population in general. Even so, the number of doctors who presented this factor is worrisome, and is the real reflection of bad diet, lack of exercise, and other unhealthy lifestyles, revealing that long hours of work, having more than one job, increased access to fast food (hypercaloric consumption), among others, as in an urban population, directly influences unhealthy lifestyles and the development of type 2 diabetes, added to the lack of programs for prevention and modification of lifestyles.

The association between age and risk obtained statistically significant values. At an older age, the risk of developing DM increases, taking the cut-off point at 45 years, which is in line with the literature.' On average physicians were 50 years old, which makes them susceptible to suffering diabetes.

The statistical association between sex and risk of type 2 diabetes was not statistically significant, suggesting that sex does not influence the risk of DM, other studies indicate it only shows a relation when it is associated with overweight, obesity and central obesity. ${ }^{22}$

Physical activity and BMI did not show to be related. This is because of the fact that the test does not evaluate the complete history of the subject, hence it only tests the time the interview was performed (transversal study), reflected that many of the participants were overweight or obese, but many were physically active. Another reason may be that BMI does not differentiate between the percentage of body fat and the percentage of muscle mass and takes it as a single data the weight, that is why there were people who exercised and had a low fat percentage, but a high percentage of muscle mass, and were classified with a BMl greater than $25 \mathrm{~kg} / \mathrm{m2}$. In contrast, the association between physical activity and abdominal circumference (central obesity) was statistically significant since this represents only abdominal fat (visceral fat) which is the most specific for the risk of developing DM.

The relationship between diet and BMI, as well as the association between diet and abdominal circumference, did not obtain statistically significant results. The reason is that the variable diet in this study only involves the consumption of daily fruits and vegetables (fiber and complex carbohydrates), which have demonstrated the reduction of risk, decreasing BMI and waist circumference, 17 even though from the $84 \%$ of the subjects studied that consumed these foods, $63 \%$ of them had central obesity and $78 \%$ were overweight and obese. This indicates that there are other factors involved in this complex relationship, which according to research would be hypercaloric diets, uncontrolled feeding schedules and high carbohydrate loading at night. ${ }^{17}$

More than 3 quarters of the study population presented risk of developing type 2 diabetes mellitus. The risk was distributed in $43 \%$ at a slightly elevated risk ( 1 in 25 will develop the disease), $23 \%$ moderate risk ( 1 in 6 will suffer from DM) , 13\% high risk ( 1 in 3 ) and $1 \%$ high risk ( 1 in 2 will develop the disease), which makes them a susceptible population, due in large part to the lifestyles that doctors take throughout their professional preparation, both in undergraduate programs, specialty degrees or subspecialties rand many other factors that increase the risk, together with the lack of intervention by the health system, the entities for which they work and the individual disinterest for health and prevention. Type 2 diabetes mellitus is a disease that can be prevented by knowing the factors present in an individual.

Figure 5. Stratification of the risk of having type 2 diabetes mellitus in 10 years in physicians from 40 to 60 years old.

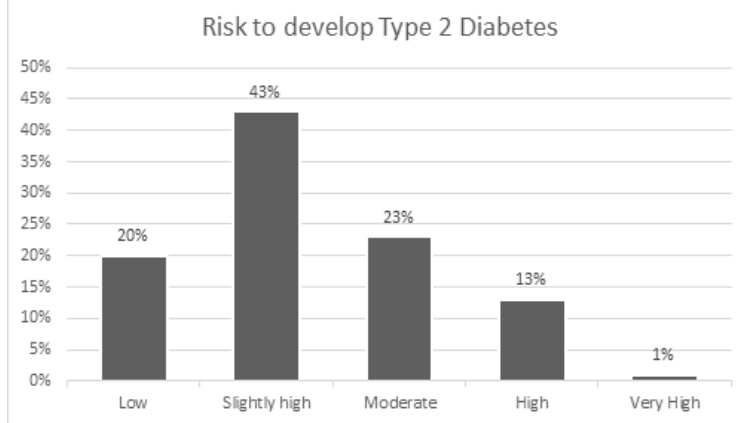

Within the limitations found by the researchers was a refusal rate to participate in the study of $12 \%$, which exceeds the estimated $10 \%$. Another limitation was that there was no database of doctors where those who had pre-diabetes and diabetes could be ruled out. I addition It could take in consideration other factors like smoking, alcohol consumption, stress level, specialty. Although the measurements could be standardized using the same instruments (digital weighing, measuring rod and metric tape) for all the measurements. Interviewing doctors from three different institutions, makes the study more representative of the medical profession, in addition this is the 
first investigation in physicians looking for the risk factors they have to develop type 2 diabetes mellitus.

\section{Conclusions}

Doctors are at an average age of 50 years old, present a sedentary lifestyle and most are found to be overweight or obese, adding that more than half present central obesity. Age, physical inactivity and central obesity are risk factors present in physicians to develop type 2 diabetes mellitus. Eight out of ten physicians studied are at risk of developing type 2 DM over a ten-year period, of which 4 are at a slightly elevated risk, 2 are moderate, one are high-risk of DM. 


\section{References}

1. American diabetes Association. Standards of medical care in diabetes-2016. Diabetes Care. 2016 Jan; 39(1).

2. Hernández Ávila M, Gutiérrez JP, Reynoso Noverón N [Diabetes mellitus in Mexico: The state of the epidemic]. Salud Pública Mex. 2013; 55(2):129-36. esp

3. Olaiz Fernández C, Rojas R, Aguilar Salinas CA, Rauda ], Villalpando S. [Diabetes mellitus in Mexican adults: Results of the 2000 National Health Survey]. Salud Pública Mex. 2007; 49(3):331-37. esp

4. Moreira JP. [Diabetes Mellitus in Guatemala: Epidemiological Aspects]. Rev Guatem Cardiol. 2014; $24 \operatorname{Maz}(1): 34-38$. esp

5. Zeceña DW. [Smoking, alcoholism, obesity and physical condition in resident physicians: Comparative study on admission and discharge of Post-degree specialties at Hospital Roosevelt, Hospital San Juan de Dios and Instituto Guatemalteco de Seguridad Social]. [thesis of medical doctor degree]. Guatemala: Universidad de San Carlos de Guatemala, Facultad de Ciencias Médicas; 1994. esp

6. López Castillo MR. [Mortality in the Guatemalan Medical Association: data collection from 1 January 2003 to 31 December 2009. Rev Col Médicos y Cir Guatemala. 2009;4(1):33-5. esp

7. Aguilar Barojas S. [Formulas for the calculation of the sample in health research]. Salud en Tabasco. 2005; 11(1-2):333-338. esp

8. Lindstrom J, Tuomilehto J. The diabetes Risk Score: A practical tool to predict type 2 diabetes risk. Diabetes Care. 2003; 26 (3):725-731.

9. Soriguer F, Valdés S, Tapia MJ, Esteva I, Ruiz de Adana MS, Almaraz MC, et al. [FINDRISC validation for predicting the risk of type 2 diabetes in a population in southern Spain: Estudio Pizarra]. Med Clin. 2012 Abr; 138 (9): 371-376. esp

10. Franciosi M, De Berardis $G$, Rossi MCE, Sacco M, Belfiglio M, Pellegrini $F$ et al. Use of the diabetes Risk Score for Opportunistic Screening of Undiagnosed diabetes and Impaired Glucose Tolerance: The IGLOO (Impaired Glucose Tolerance and Long-Term Outcomes Observational) study. diabetes Care. 2005 May; 28 (5): 1187-1194.

11. Rathmann W, Martin S, Haastert B, Icks A, Holle R, Lowel H, et al. Performance of Screening Questionnaires and Risk Scores for Undiagnosed diabetes: The KORA survey 2000. Arch Intern Med. 2005 Feb; 165: 463-441.
12. Brito Núñez N], Brito Núñez JD, Ruiz-Rendón CM. [Risk of diabetes in a rural community of Sotillo municipality. Monagas State]. Venezuela. Rev Venez Endocrinol Metab. 2014 Oct; 12(3):167-176. esp

13. Arnold Rodríguez M, Arnold Domínguez Y, Alfonso Hernández Y, Villar Guerra C, González Calero TM. [Research and prevention of type 2 diabetes mellitus in at-risk population]. Rev Cubana Hig Epidemiol. 2012; 50(3):380-391. esp 14. Ochoa Orozco SA, Moreno Gutiérrez PA, Echeverri Cataño LF, Orozco Escobar A, Mondragón Cardona A, Villegas Rojas Soraya. [Cardiovascular risk and diabetes in the prison population of Pereira, Colombia, 2010]. Revista Médica Risaralda. 2012 Dic; 18(2):129-133. esp

15. Palacios-Rodríguez RG, Paulín-Villalpando P, López-Carmona JM, Valerio-Acosta M, Cabrera-Gaytán DA. [Metabolic syndrome in health personnel of a family medicine unit]. Rev Med Inst Mex Seguro Soc. 2010;48(3):297-302. esp

16. Guzmán Melgar I. [Current status of cardiovascular risk factors in general population in Guatemala]. Rev Guatem Cardiol. 2014 Mar;24(1):3-8. esp 17. Tuomilehto J, Lindström J, Eriksson J G, Valle T T, Hämäläinen H, Ilanne-Parikka $\mathrm{P}$, et al. Prevention of type 2 diabetes mellitus by changes in lifestyle among subjects with impaired glucose tolerance. N Engl J Med. 2001 May; 344 (18): 1343-1350.

18. Valdés Ramos I E, Bencosme Rodríguez N. [Frequency of arterial hypertension and its relationship with some clinical variables in patients with type 2 diabetes mellitus]. Rev Cuba Endocrinol. 2009; 20(3):77-88. esp 19. Vicente Sánchez B, Vicente Peña E, Altuna Delgado A, Costa Cruz M. [Identification of individuals at risk of developing type 2 diabetes]. Rev Finlay. 2015; 5(3):22-27. esp 20. Cornejo Guerra JA. [Diabetes Eradication in Guatemala: A Possible Dream]. Rev Ciencia, Tecnología y Salud. 2015;2(1):75-83. esp

21. Cuba J, Ramírez T, Olivares B, Bernui I, Estrada E. [Lifestyles and their relation with excess weight, in the medical residents of a national hospital]. An Fac med. 2011;72(3):205-10. esp

22. Moreno González MI. [Waist Circumference: An Important and Useful Measurement of Cardiometabolic Risk]. Rev Chil Cardiol. 2010;29(1):85-7. esp 23. Aráuz-Hernández AG, Guzmán-Padilla S, Roselló-Araya M. [Abdominal circumference as an indicator of cardiovascular disease risk]. Acta méd costarric. 2013 Jul-Sep;55(3):122-7. esp

\section{Acknowledgments}

The authors would like to thank Facultad de Ciencias Médicas of Universidad de San Carlos de Guatemala, for the guidance to accomplish this research, to Emily Ochaeta and Doris Lima for proofreading the article.

\section{Conflict of Interest Statement at Funding}

The present study was a graduation project of Medical Doctor of the Universidad de San Carlos of Guatemala. The information and results of this study were generated for eminently scientific purposes. The investigators state that the present study does not have remunerative or commercial profit objectives.

\section{Author Contributions}

Conception and design the work/idea, collect data/obtaining results: EDC, GV, ES. Analysis and interpretation of data: EDC, GV, ES, CO, CC, HS. Write de manuscript: EC, GV. Critical revision of the manuscript, approval of the final version: G0, CC, HS. Statistical Advice: CO, CC.

\section{Cite as:}

Castro ED, Velásquez GA, Lineker Santos E, Oliva GA, Chang CE, Soto HF.. Risk to Develop Type 2 Diabetes Mellitus according to FINDRISC tool in Guatemalan Physicians aged 40-60 years. Int J Med Students. 2017 Jan-Apr;5(1):20-25. 